\title{
The role of automated sorting in the recovery of aluminium alloys waste
}

\author{
C.A. Nogueira, M.A. Trancoso, F. Pedrosa, A.T. Crujeira, \\ P.C. Oliveira \& A.M. Gonçalves \\ Laboratório Nacional de Energia e Geologia - LNEG, Lisboa, Portugal \\ F. Margarido \& R. Novais Santos \\ Instituto Superior Técnico, Universidade de Lisboa, IN+, Lisboa, Portugal \\ F. Durão \& C. Guimarães \\ Instituto Superior Técnico, Universidade de Lisboa, CERENA, Lisboa, Portugal
}

\begin{abstract}
A large number of aluminium alloys with varying alloying elements are present in vehicle structures and components, as well as in other household equipment. The recycling of these alloys is nowadays processed to low quality metal products due to high level of contamination, hindering the upgrading of recycling rates. The development and application of automated sorting technologies capable to detect, select and separate different alloy types could be of crucial importance in the progression of the recycling loop. This paper addresses the importance of sorting based on a study on the characterization of Al alloys in non-ferrous fraction of shredder plants.
\end{abstract}

\section{INTRODUCTION}

Light alloys, namely based of aluminium and, more recently, magnesium, have been progressively utilized in many equipments such as vehicles, aiming at reducing weight and fuel consumption. The driving forces for substituting classic alloys (namely those steel-based) for such new ones have been obvious economic but also environmental, trying to save resources and decreasing emissions. To answer to several specifications for a wide range of applications, numerous alloy types have been developed and applied in products. Such alloys have different properties (mechanical, chemical, electrical, etc.) conferred by the addition of alloying elements (e.g. Si, $\mathrm{Mg}, \mathrm{Mn}, \mathrm{Cu}, \mathrm{Zn}$ ) with different combinations and contents.

Due to the high variety of alloys, recycling of aluminium fractions produced in shredder plants is only suitable for manufacture of low purity Al alloys. Regarding most common wrought type alloys, typically with low Si content, the presence of cast alloy fragments, with high Si concentration, would be deleterious. So recycling of aluminium for producing wrought alloys becomes difficult. This is just one example of multiple cases where the production of specific Al alloys can be seriously affected by using recycled materials. Thus, the option is the use of substantial quantities of pure aluminium coming from primary resources or as much use recycled aluminium collected from very specific sources. Aluminium from recycling metal-bearing residues such as endof-life vehicles, electric and electronic wastes or other household appliances is mostly destined to downcycling schemes.

To overcome these bottlenecks the development of efficient technologies for separating some relevant $\mathrm{Al}$ alloy groups would be highly welcome. In this domain, automated sorting devices that can detect alloying elements can play a significant role in boosting Al recycling industry. This paper discusses some aspects regarding the separation of the most important alloy series based 


\section{Wastes: Solutions, Treatments and Opportunities}

Editors

Cândida Vilarinho \& Fernando Castro

University of Minho, Guimarães, Portugal

Mário Russo

Polytechnic Institute of Viana do Castelo, Viana do Castelo, Portugal

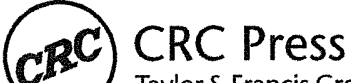

Taylor \& Francis Group Boca Raton London New York Leiden

CRC Press is an imprint of the

Taylor \& Francis Group, an informa business

A BALKEMA BOOK 